\title{
Exportações e importações do agronegócio brasileiro e seus determinantes no período 1995-2009
}

Adriano Stockly ${ }^{*}$

Eziquiel Guerreiro**

Augusta Pelinski Raiher ${ }^{* *}$

\begin{abstract}
RESUMO - Este estudo teve por objetivo analisar a evolução das exportações e importações do agronegócio brasileiro e seus determinantes no período de 1995 a 2009. Como resultado, identificou-se que as exportações cresceram em média 4,63\% ao ano, enquanto que as importações tiveram uma queda anual de $4,46 \%$. No caso dos determinantes das exportações, verificou-se que a taxa de câmbio efetiva real não influenciou as exportações do agronegócio, enquanto que a renda internacional e o índice de commodities alimentação exerceram um efeito positivo ao nível de significância adotado. No caso das importações, pode-se dizer que a taxa de câmbio determinou-a negativamente, enquanto que o índice de commodities geral influenciou-a positivamente, e para o PIB do Brasil não se captou nenhuma influência sua sobre as importações.
\end{abstract}

Palavras-chave: Agronegócio brasileiro. Exportações. Importações.

\section{INTRODUÇÃO}

O agronegócio é um dos principais setores da economia brasileira. Sua importância se verifica na geração de riqueza e renda, na demanda por emprego, na formação de divisas, aumentando e diversificando as exportações do país. Dados do CEPEA (2011) demonstram que a participação do agronegócio no PIB brasileiro foi de 23\% em 2009, contribuindo com $43 \%$ das exportações, sendo responsável por 35\% dos empregos gerados, o que representa em torno de $12 \%$ da população economicamente ativa.

Essa vocação natural para a agropecuária e para todos os negócios relacionados à suas cadeias produtivas advém do clima diversificado que o país apresenta, das chuvas regulares, da energia solar abundante e dos 388 milhões de hectares de terras agricultáveis férteis e de alta produtividade, dos quais 90 milhões ainda não foram exploradas (BORGES, 2007).

Neste sentido, considerando a relevância deste setor na economia do país, este traba-

\footnotetext{
* Graduado em economia pela Universidade Estadual de Ponta Grossa. É funcionário do Banco do Brasil. Endereço eletrônico: adrianostockly@yahoo.com.

** Mestre em economia pela Universidade de São Paulo. É professor do Departamento de Economia da Universidade Estadual de Ponta Grossa. Endereço eletrônico: eziquiel@uepg.br.

*** Doutora em economia pela Universidade Federal do Rio Grande do Sul. É professora adjunta do Departamento de Economia da Universidade Estadual de Ponta Grossa. Endereço eletrônico: apelinski@gmail.com.
} 
lho busca analisar a evolução das exportações e importações do agronegócio brasileiro e seus determinantes no período de 1995 a 2009. Para isso, apresenta-se, além desta, mais três seções. $\mathrm{Na}$ segunda seção trabalham-se os elementos metodológicos norteadores deste trabalho. $\mathrm{Na}$ sequência são apresentados os resultados, finalizando com as considerações.

\section{ELEMENTOS METODOLÓGICOS}

Diversos autores analisam os elementos propulsores das importações e exportações do agronegócio no Brasil. Carvalho e De Negri (2000), por exemplo, utilizaram-se de um modelo de substituição imperfeita em equações de comércio exterior para explicar o comportamento das importações e exportações de produtos agropecuários no Brasil entre 1977 e 1998. Neste trabalho, os autores verificaram que as exportações eram significativamente afetadas pelo nível de atividade mundial e pouco afetadas pela taxa de câmbio. No caso das importações, comprovaram que eram basicamente dependentes da capacidade instalada e dos preços relativos, confirmando ainda que os importadores faziam suas compras de acordo com as alterações do câmbio real.

Em Barros, Bacchi e Burnquist (2002) realizou-se a estimação de equações de oferta de exportação de produtos agropecuários brasileiros de 1992 a 2000, onde a renda interna apresentou relação inversa com a exportação. A taxa de câmbio foi o fator mais determinante, revelando que um aumento da mesma tende a elevar o volume de exportações de produtos agropecuários. Outra relação positiva encontrada foi entre o incremento dos preços internacionais, que por um lado favorece as exportações, e, por outro, reduz as importações.

Oliveira e Guerreiro (2006), em estudo sobre fatores determinantes das importações e exportações brasileiras de bens e/ou serviços nas relações com os Estados Unidos e com o resto do mundo de 1990 a 2003, obtiveram como resultado que a variável de maior influência nas exportações era a renda externa. E, nas importações de bens dos Estados Unidos, os autores constataram maior sensibilidade em relação à taxa de câmbio.

Diante dessas argumentações e considerando o modelo descrito por Blanchard (2001), no qual as exportações dependem da renda estrangeira e da taxa real de câmbio, e as importações são determinadas pela renda interna e pela taxa real de câmbio, então as estimativas construídas para captar os determinantes das exportações (1) e os determinantes das importações (2) do agronegócio brasileiro, no período de 1995 a 2009, foram²:

1 Os valores nominais referentes ao PIB dos Estados Unidos, índice de commodities geral e de alimentos, importações e exportações, foram deflacionados pelo IPC-EUA, enquanto a variável PIB brasileiro foi deflacionada pelo IGP-DI, e a taxa de câmbio pelo INPC, tendo como base o mês de janeiro de 1995. 


$$
L X=b_{0}+b_{1} L T C+b_{2} L Y I+b_{3} L I C A
$$

Em que: $L X$ representa o logaritmo das exportações do agronegócio brasileiro, obtido junto ao site do MAPA; LTC é a taxa de câmbio efetiva real logaritmizada, com dados oriundos do IPEADATA; a variável LYI indica o logaritmo da renda externa, representada pelo PIB dos Estados Unidos, com ajuste sazonal, coletada junto ao IPEADATA; e LICA corresponde ao índice de commodities alimentação logaritmizado, obtido na revista Conjuntura Econômica.

$$
L M=b_{0}+b_{1} L T C+b_{2} L Y B R+b_{3} L I G C
$$

Em que: $L M$ representa o logaritmo das importações do agronegócio brasileiro em dólares, com dados do MAPA; LTC é a taxa de câmbio efetiva real logaritmizada; LYBR corresponde à renda interna em $\log$, sendo a fonte o IBGE; e LIGC é o logaritmo do índice de commodities geral, obtido junto à Conjuntura Econômica.

Por fim, visando assegurar que os pressupostos do MQO (Mínimos Quadrados Ordinários) estavam sendo atendidos, fez-se, para ambas estimativas, os testes: Shapiro Wilk, para analisar se os resíduos de cada modelo apresentavam distribuição normal; Test of First and Second Moment, cujo objetivo era o de verificar se os modelos eram homocedásticos; Durbin-Watson, como teste para autocorrelação serial; e o fator variável de inflação (FIV), visando diagnosticar a multicolinearidade.

\section{ANÁLISE DOS RESULTADOS}

\subsection{AS EXPORTAÇÕES DO AGRONEGÓCIO BRASILEIRO: 1995 A 2009}

Segundo Barros e Silva (2006), o agronegócio tem sido fundamental para a economia brasileira. Por meio de revoluções tecnológicas, alcançaram-se aumentos de produtividade que contribuíram para a competitividade e eficiência do setor. Os autores argumentam que, principalmente após o Plano Real, o desempenho do agronegócio proporcionou queda real de mais de $20 \%$ dos preços aos consumidores, beneficiando a sociedade como um todo e facilitando a manutenção das baixas taxas de inflação observadas no período, além de ter oferecido saldos comerciais entre 11 e 28 bilhões de dólares por ano, atenuando, assim, os déficits comerciais que de outra forma poderiam tornar-se insuportáveis para o país.

Neste sentido, a análise do desempenho das exportações do agronegócio no Brasil a 
partir de 1995 demonstra a existência de um crescimento médio anual ${ }^{2}$ de 4,63\%, alcançando o valor máximo em 2008, e o menor valor em 2000 (Gráfico 1). Verifica-se que de 1995 até 2000 existiu uma tendência de decrescimento das exportações, revertendo o quadro a partir de 2001, com crescimentos anuais significativos até 2008.

No período de tendência de apreciação cambial brasileira, que correspondeu aos anos de 2003 a 2009 (Gráfico 1), onde o câmbio real apreciou em média 4,86\% a.a. ${ }^{3}$, as exportações do agronegócio cresceram em termos reais numa média anual de 8,12\%, enquanto que, entre 1999 a 2002, período onde a taxa de câmbio se depreciou em 4,55\% a.a., as exportações aumentaram em apenas 2,10\% a.a. Como a teoria econômica argumenta que uma taxa de câmbio apreciada favorece as importações, ao passo que uma taxa de câmbio depreciada contribui para as exportações, então esses dados sinalizam que entre 1995 a 2009 existiram variáveis mais importantes na determinação das exportações que a taxa de câmbio real.

GRÁFICO 1 - EVOLUÇÃO DO ÍNDICE DAS EXPORTAÇÕES DO AGRONEGÓCIO BRASILEIRO, DA TAXA DE CÂMBIO, DO PIB-EUA E DO ÍNDICE DE ALIMENTAÇÃO - 1995-2009

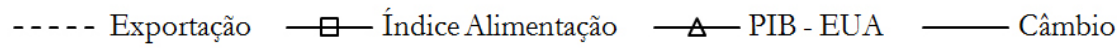

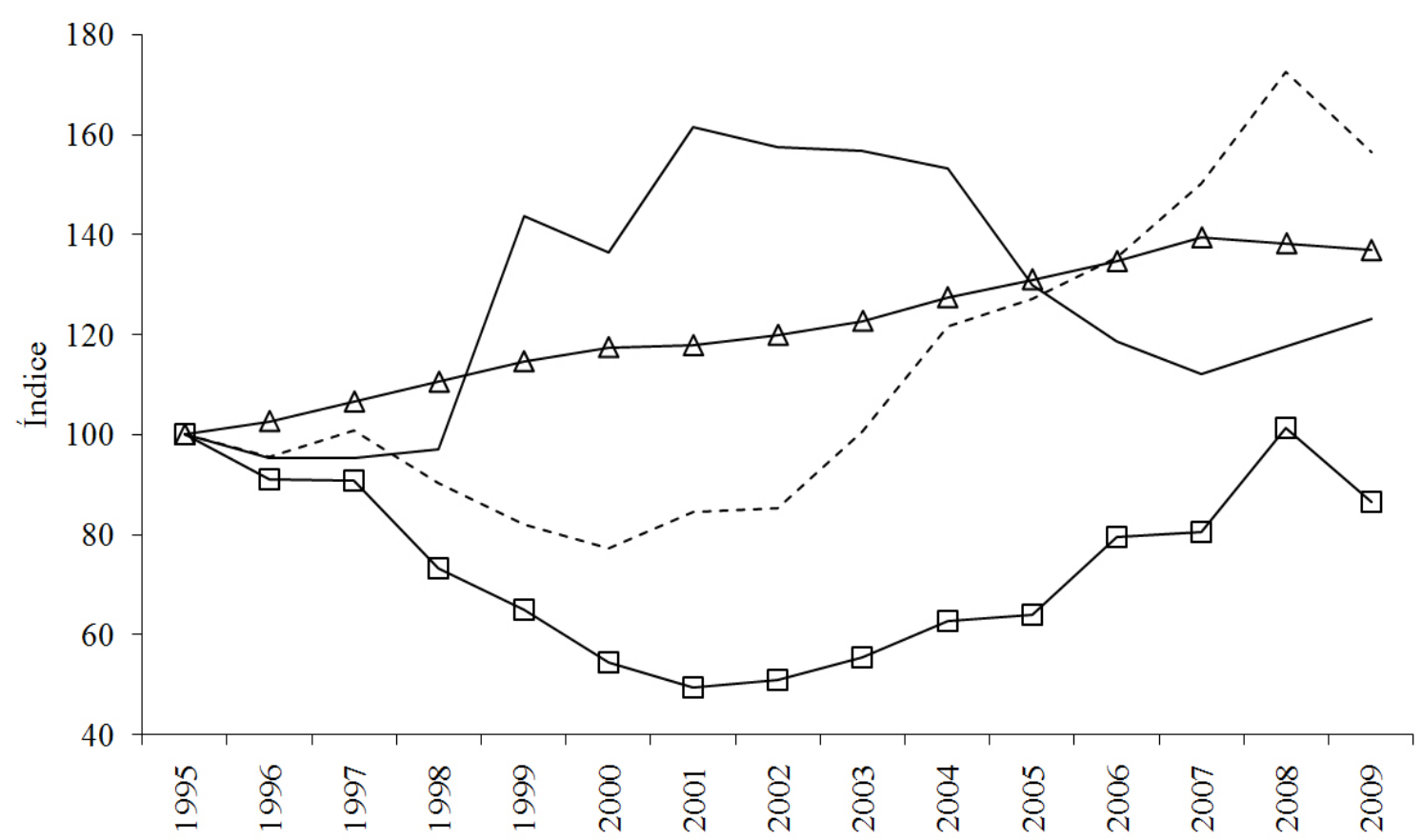

FONTE: Resultado da pesquisa.

E é exatamente isso que se observa quando se relaciona as exportações do agronegócio com algumas variáveis selecionadas (Tabela 1), não identificando nenhuma relação entre a

2 Calculado mediante a relação $\mathrm{Y}=\mathrm{f}(\mathrm{t})$ na forma exponencial, onde $\mathrm{Y}$ é exportação e t é tempo.

3 Calculado pela taxa geométrica de crescimento. 
taxa de câmbio e as exportações no período analisado. Ao mesmo tempo, a renda internacional, representada pelo PIB dos Estados Unidos, mostrou-se relevante, em que um aumento de 1\% nessa variável implica num acréscimo de 1,85 \% nas exportações do agronegócio brasileiro. Isso significa que o efeito que a renda internacional tem sobre as exportações é mais que proporcional, sugerindo certa vulnerabilidade destas em relação ao cenário internacional.

Além disso, observa-se, por meio da Tabela 1, uma influência positiva do índice de commodities alimentação sobre as exportações do agronegócio, destacando que um incremento de 1\% no índice de commodities alimentação tende a gerar uma elevação de 0,69\% nas exportações.

Assim, os resultados demonstram que a renda externa e o índice de commodities alimentação influenciaram positivamente as exportações do agronegócio, não captando qualquer efeito da taxa de câmbio. No trabalho realizado por Oliveira e Guerreiro (2006), eles também encontraram significância para a renda externa, da mesma forma que em estudo realizado por Carvalho e De Negri (2000), a taxa de câmbio afetava muito pouco as exportações brasileiras.

TABELA 1 - RESULTADO DOS MODELOS ECONOMÉTRICOS (1) E (2)

\begin{tabular}{|c|c|c|c|c|c|c|}
\hline \multirow{2}{*}{ Modelo estimado } & \multicolumn{4}{|c|}{ Parâmetros } & \multirow{2}{*}{$\mathbf{R}^{2}$} & \multirow{2}{*}{$\mathbf{F}$} \\
\hline & $b_{0}$ & $b_{1}$ & $\mathbf{b}_{2}$ & $b_{3}$ & & \\
\hline $\begin{array}{l}L X=b_{0}+b_{1} L T C+b_{2} L Y I+b_{3} L I C A \\
L M=b+b_{1} L T C+b_{2} L Y B R+b \text { LIGC }\end{array}$ & $\begin{array}{l}-7,4448^{*} \\
6,7097^{\text {ns }}\end{array}$ & $\begin{array}{l}0,0563^{\text {ns }} \\
-0,8230^{*}\end{array}$ & $\begin{array}{r}1,8543^{*} \\
-0,2884^{\mathrm{ns}}\end{array}$ & $\begin{array}{l}0,6972^{*} \\
0,6272^{*}\end{array}$ & $\begin{array}{l}0,95 \\
0,91\end{array}$ & $\begin{array}{l}62,41^{*} \\
23,13^{*}\end{array}$ \\
\hline
\end{tabular}

FONTE: Resultado da pesquisa.

NOTA: *Significativo a 5\%; ns: não significativo a 5\%. LX representa o logaritmo das exportações do agronegócio; LTC é a taxa de câmbio efetiva real logaritmizada; a variável LYI indica o logaritmo da renda externa, representada pelo PIB dos Estados Unidos; LICA corresponde ao índice de commodities alimentação logaritmizado; $L M$ representa o valor das importações do agronegócio logaritmizado; LYBR corresponde ao logaritmo da renda interna; LIGC é o índice logaritmizado de commodities geral.

\subsection{AS IMPORTAÇÕES DO AGRONEGÓCIO BRASILEIRO: 1995 A 2009}

Dentro da pauta de importação do agronegócio predominam matérias-primas agropecuárias essenciais para o desempenho do setor, como fertilizantes e defensivos (BRASIL, 2011). Isso demonstra que o sucesso percebido nesse setor, com aumento de produtividade crescente, depende, em certo ponto, das importações que são feitas. Neste sentido, identificar os fatores determinantes das importações é essencial para a própria competitividade do país neste segmento.

O Gráfico 2 apresenta a evolução das importações e de algumas variáveis importantes na determinação da mesma, em conjunto com a evolução das exportações no período de 1995 a 2009. Observa-se que as importações tiveram um decréscimo percentual médio de 4,46\% ao ano, enquanto que as exportações cresceram 4,63\% ao ano. Se compararmos a evolução do 
índice das exportações com o das importações, perceberemos um distanciamento entre elas, elevando-se ano a ano o saldo comercial do agronegócio brasileiro, passando de US\$12 bilhões em 1995 para US\$26 bilhões em 2009 (MAPA, 2010), demonstrando o aumento crescente da produtividade deste setor.

Ao mesmo tempo em que as importações tiveram taxas de crescimento decrescentes, o PIB real do país cresceu 1,49\% ao ano no período em análise. A teoria econômica argumenta que quanto maior a renda interna, maior tende a ser o montante de importações; no entanto, conforme demonstra o Gráfico 2, visualmente existe uma diferença entre a teoria e a verificação empírica desta relação, sendo, portanto, um indicativo de que a renda interna brasileira não afetou significativamente as importações do agronegócio no período analisado.

Por outro lado, a análise da evolução do câmbio versus as importações evidencia uma relação entre as duas variáveis (Gráfico 2). Nota-se que nos anos de 1995 a 1999, onde o país trabalhou com bandas cambiais, com taxa de câmbio valorizada, as importações decresceram; no período de 1999 a 2002, no qual houve uma depreciação anual de 4,55\%, as importações diminuíram (13,39\%); ao passo que, de 2003 a 2009, quando se teve uma tendência de apreciação anual (4,55\%), o ritmo de importação se elevou anualmente em 11,05\%. Neste contexto, os dados, em geral, sinalizam uma possível relação existente entre a taxa de câmbio e as importações brasileiras do agronegócio.

GRÁFICO 2 - EVOLUÇÃO DO ÍNDICE DAS IMPORTAÇÕES DO AGRONEGÓCIO BRASILEIRO, DA TAXA DE CÂMBIO, DO PIB E DO ÍNDICE DE PREÇO GERAL -1995-2009

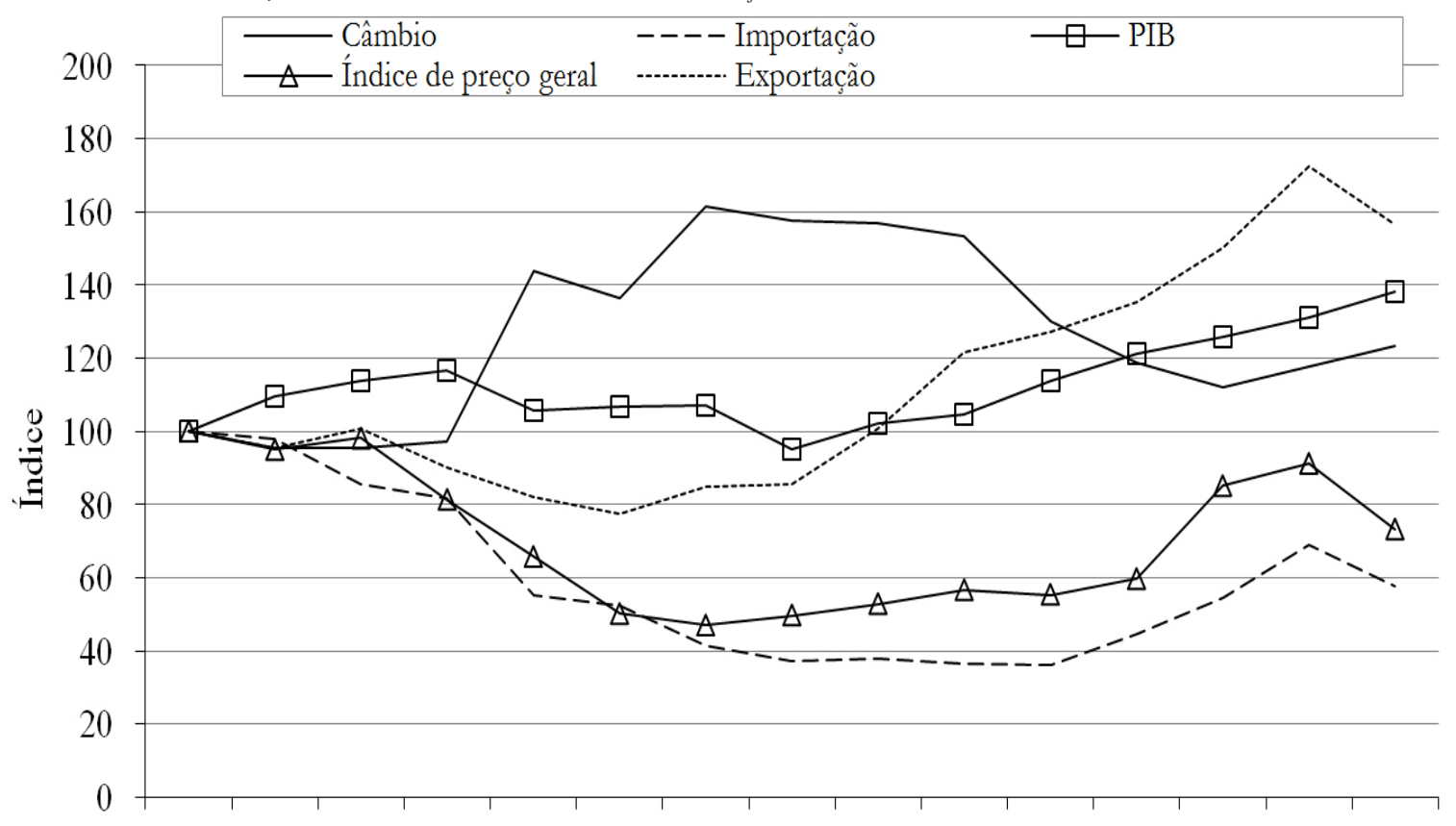

199519961997199819992000200120022003200420052006200720082009

FONTE: Resultado da pesquisa. 
Com o propósito de identificar a influência da taxa de câmbio, do PIB do Brasil e do índice de commodities geral sobre as importações do agronegócio brasileiro, estimou-se (2), apresentado os resultados na Tabela 1. Como pode ser visto, os sinais dos parâmetros estão de acordo com a teoria econômica, com exceção apenas do índice de commodities geral. Verificase que o PIB do Brasil não influenciou as importações do agronegócio brasileiro ao nível de significância de 5\%, resultado que corrobora com a análise feita a priori acerca da evolução das importações versus o crescimento do PIB.

Já a taxa de câmbio foi estatisticamente significativa, em que uma queda de 1\% nessa variável (o que implica numa apreciação cambial) tende a resultar num acréscimo de $0,82 \%$ nas importações. Isso vai de encontro com os resultados apresentados anteriormente, onde se verificou uma maior fomentação das importações principalmente nos anos onde se tinha uma apreciação cambial.

Por fim, o índice de commodities geral influenciou positivamente as importações, destacando que um aumento de $1 \%$ no índice de commodities geral gera uma elevação de 0,62\% nas importações. A princípio, tal variável veio com um sinal contrário ao que se esperava, entretanto, como neste índice de commodities geral se consideram produtos que têm determinado valor agregado e que na grande maioria das vezes possuem um impacto direto sobre a produtividade, então esse resultado indica que mesmo elevando-se os preços desses importados, dada a dependência e o próprio crescimento interno, sua demanda tende a se elevar.

\section{CONSIDERAÇÕES FINAIS}

O agronegócio brasileiro tem sido um setor estratégico para a evolução da economia, atuando na produção, geração de emprego, geração de divisas, servindo como base para a economia. Neste sentido, este estudo teve como objetivo analisar a evolução das exportações e importações do agronegócio brasileiro e seus determinantes, no período de 1995 a 2009.

Os resultados demonstraram uma evolução positiva das exportações em contraste com um decréscimo das importações durante o período analisado. No que se refere às variáveis determinantes, observou-se que o volume das exportações é bem menos sensível ao câmbio do que o das importações, destacando que uma desvalorização reduz significativamente o valor desta última. Macroeconomicamente, este é um resultado importante por apontar um caminho para a economia de divisas do país. Entretanto, reduções muito grandes das importações podem comprometer o próprio desempenho do setor, principalmente pelo encarecimento dos insumos essenciais para o seu crescimento.

Além do câmbio, o preço externo influenciou positivamente as importações do agro- 
negócio, da mesma forma que este também exerceu um efeito sobre as exportações. Ao mesmo tempo, estas também foram determinadas positivamente pela renda externa. Assim, de forma geral, o estudo detectou certa dependência tanto das exportações como também das importações por variáveis internacionais (preços externos e renda externa), não havendo dúvidas de que os períodos em que os preços de commodities e a renda externa são mais elevados favorecem significativamente o desempenho deste setor.

Diante disso, políticas públicas que elevem a competitividade do agronegócio - com um melhoramento na infraestrutura nacional (portos, estradas, dentre outros fatores que contribuam para o avanço do armazenamento e dos transportes dos produtos desse setor) e com geração de novas tecnologias que visem elevar a produtividade e que contribuam na agregação de valor nos bens desse setor - tornam-se necessárias, contribuindo para uma maior inserção sua no cenário internacional.

\section{REFERÊNCIAS}

BARROS, G. S. C.; SILVA, S. F. O saldo comercial do agronegócio e o crescimento da economia brasileira. CEPEA-ESALQ/USP, São Paulo, jan. 2004. Disponível em: < http://www. cepea.esalq.usp.br/pdf/saldo_cresc.pdf $>$. Acesso em: 15/3/2010.

BARROS, G. S. C.; BACCHI, M. R. P.; BURNQUIST, H. L. Estimação de equações de oferta de exportações de produtos agropecuários para o Brasil (1992/2000). Texto para Discussão IPEA, Brasília, n. 865, mar. 2002. Disponível em: <http://www.ipea.gov.br/pub/td/2002/ td_0865.pdf>. Acesso em: 15/03/2010.

BLANCHARD, O. Macroeconomia: teoria e política econômica. Tradução (da 2. ed. original) de: MONTEIRO, M. J. C. Rio de Janeiro: Elsevier, 2001. p. 397-400.

BORGES, A. O grande desafio do agronegócio no Brasil. 2007. Disponível em: < http:// www.empreendedorrural.com.br>. Acesso em: 12/2010.

CARVALHO, A.; DE NEGRI, J. A. Estimação de equações de importação e exportação de produtos agropecuários para o Brasil. Texto para Discussão IPEA, Brasília, n. 698, 2000. Disponível em: <http://www.ipea.gov.br/pub/td/td_2000/td_698.pdf>. Acesso em: 15/5/2010.

CEPEA. Disponível em: <http://www.cepea.esalq.usp.br/pib/other/Pib_Cepea_1994_2009. xls>. Acesso em: 01/2011.

MAPA - Ministério da Agricultura, Pecuária e Abastecimento. Disponível em: <http://www. agricultura.gov.br/>. Acesso em: 1/3/2010.

OLIVEIRA, C. R.; GUERREIRO, E. Determinantes das exportações e importações brasileiras de bens e serviços no período de 1990 a 2003. In: GESTÃO estratégica para a competitividade. Ponta Grossa: UEPG, 2006. p. 11-19. 